\title{
Inhibition of PAF-induced expression of CD11b and shedding of L-selectin on human neutrophils and eosinophils by the type IV selective PDE inhibitor, rolipram
}

\author{
C. Berends*, B. Dijkhuizen*, J.G.R. de Monchy*, A.E.J. Dubois*, \\ J. Gerritsen**, H.F. Kauffman*
}

Inhibition of PAF-induced expression of CDIIb and shedding of L-selectin on human neutrophils and eosinophils by the type IV selective PDE inhibitor, rolipram. $C$. Berends, B. Dijkhuizen, J.G.R. de Monchy, A.E.J. Dubois, J. Gerritsen, H.F. Kauffman. (C)ERS Journals Ltd 1997.

ABSTRACT: We quantitatively determined whether the selective phosphodiesterase (PDE) inhibitor, rolipram, inhibits changes in the adhesion molecules CD11b and L-selectin on platelet-activating factor (PAF)-stimulated human neutrophils and eosinophils in vitro.

Incubations were performed in human whole blood obtained from healthy volunteers, to restrict activation by purification procedures and to simulate in vivo conditions, in which different cell types may interact, more closely. Receptor expression was measured after fixation of cells, using monoclonal antibodies and flow cytometry.

Concentration-dependent inhibition of the PAF-induced CD11b expression and L-selectin shedding for neutrophils and eosinophils was observed with rolipram, dibutyryl cyclic adenosine monophosphate (cAMP), prostaglandin $\mathbf{E}_{2}\left(\mathrm{PGE}_{2}\right)$, and isoproterenol. However, these inhibitions did not exceed 50\%. Preincubation with rolipram $\left(10^{-8} \mathrm{M}\right)$ and subsequent incubation with isoproterenol $\left(0.5 \times 10^{-8} \mathrm{M}\right)$ or $\mathrm{PGE}_{2}\left(\mathbf{1 0}^{-8} \mathrm{M}\right)$ induced a cumulative, but not synergistic, effect. Using the combination of rolipram with isoproterenol or $\mathrm{PGE}_{2}$, inhibition of PAF-induced Lselectin shedding from eosinophils was as high as $71 \pm 28$ and $67 \pm 21 \%$, respectively. Other inhibitions were below $50 \%$.

In conclusion, rolipram inhibits CD11b expression and L-selectin shedding of platelet-activating factor-stimulated neutrophils and eosinophils in whole blood in a concentration-dependent fashion. Inhibitions did not exceed $50 \%$, even at high concentrations. The inhibition of platelet-activating factor induced shedding of $\mathrm{L}$ selectin from eosinophils with a combination of rolipram and prostaglandin $E_{2}$ or isoproterenol, however, was found to be approximately $70 \%$. Inhibition of rolling adhesion of eosinophils may, therefore, be a mode of action of type IV phosphodiesterase inhibitors.

Eur Respir J 1997; 10: 1000-1007.

Extravasation and infiltration of neutrophils and eosinophils into tissues occurs in various inflammatory lung diseases [1-3]. Local activation of these cells and release of reactive oxygen species, lipid mediators, and toxic granule constituents subsequently contributes to the pathological features of these disorders $[4,5]$. Therapeutic intervention aimed at inhibiting granulocyte infiltration may reduce the inflammatory response and limit tissue damage.

Infiltration of granulocytes is orchestrated by a number of receptors belonging to different distinct families of adhesion molecules [6,7]. During the initial step of adhesion and transendothelial migration, granulocytes roll along the vascular wall [8]. This step is mediated by reversible binding of L-selectin (lectin adhesion molecule-1 (LECAM-1), Leu8) on the granulocyte to counter structures on endothelial cells. This initial step is fol-
Depts of *Allergology and **Paediatric Pulmonology, University Hospital Groningen, Groningen, The Netherlands.

Correspondence: H.F. Kauffman

Laboratory of Allergology

Clinic for Internal Medicine

University Hospital Groningen

P.O. Box 30.001

9700 RB Groningen

The Netherlands

\section{Keywords: CD11b}

eosinophils

L-selectin

neutrophils

phosphodiesterase inhibitors

rolipram

Received: April 291996

Accepted after revision December 141996

This study was supported by grant $90.50 \mathrm{~A}$ from the Dutch Asthma Foundation. lowed by a firmer adhesion. Mac-1 (CD11b/CD18, CR3) is one of the molecules involved in this process. This molecule belongs to the $\beta_{2}$-family of integrins and may bind to intercellular adhesion molecule-1 (ICAM-1) on endothelial cells. Upon activation of the granulocyte by mediators bound to the endothelial cell surface, L-selectin is rapidly shed from the cell surface, and Mac-1 is concomitantly increased by release from intracellular stores $[9,10]$. One of the activating agents produced by endothelial cells is platelet-activating factor (PAF) [11]. The increase of CD11b expression and concomitant shedding of L-selectin is not only observed in vitro [12, 13]; a number of studies have shown increased Mac-1 expression and decreased L-selectin expression on extravasated neutrophils and eosinophils in vivo [2, 14, 15].

Animal studies have shown that infiltration of neutrophils and eosinophils can be inhibited by rolipram 
[16-18]. Rolipram inhibits phosphodiesterase (PDE) type IV, which hydrolyses cyclic adenosine monophosphate (cAMP) into the biologically inactive form 5 '-adenosine monophosphate (5'-AMP) [19]. Therefore, inhibition of PDE increases intracellular cAMP [20], which may exert various inhibitory effects, such as relaxation of airway smooth muscle and inhibition of mediator release by inflammatory cells [20-23]. Other PDE isoenzymes have been described, but type IV is the predominant type present in neutrophils and eosinophils [20, 23]. PDE inhibitors may act synergistically with receptordependent activators of adenylyl cyclase to inhibit polymorphonuclear leucocyte activation in vitro [23-25]. Currently, PDE IV inhibitors are considered one of the most promising antiasthma drugs for the future [26]. In this context, the effects of these compounds on the eosinophil is of interest.

Rolipram may inhibit rolling, adhesion and transmigration of granulocytes by direct effects on receptor numbers. In a recent study from DERIAN et al. [27], it was shown that rolipram attenuated neutrophil-endothelial adhesion by $80 \%$. Inhibition of neutrophil CD $11 \mathrm{~b}$ surface expression was observed in that study but not quantified.

In the present study, we quantitatively determined whether rolipram can inhibit the shedding of L-selectin, involved in rolling, as well as the upregulation of CD11b, involved in firm adhesion. Since purification of neutrophils and eosinophils has been shown to modulate surface expression of CD11b [28-30], a whole blood system was used. This also allowed for interactions between different cell types in blood, thus more closely approaching the situation in vivo. Hence, the results may be more indicative for the effects of rolipram in vivo than results of experiments with isolated granulocytes. In addition, we studied whether isoproterenol and prostaglandin $\mathrm{E}_{2}\left(\mathrm{PGE}_{2}\right)$ act synergistically on adhesion receptor inhibition by rolipram.

\section{Materials and methods}

\section{Subjects and reagents}

Blood was drawn from healthy volunteers, who all gave their informed consent. Eosinophil counts were normal, between 40 and 437 cells $\mu \mathrm{L}^{-1}$ of blood.

PAF (Sigma Chemical Co., St. Louis, MO, USA) was dissolved in $0.9 \% \mathrm{NaCl}$, containing $2.5 \%$ human serum albumin (HSA) at a concentration of $200 \mu \mathrm{M}$, before final dilution in Hank's balanced salt solution (HBSS, Gibco BRL Paisley, Scotland). Isoproterenol and dibutyryl cAMP (Sigma) were directly dissolved in HBSS. $\mathrm{PGE}_{2}$ (Sigma) was dissolved in absolute ethanol to obtain a stock solution of $2 \times 10^{-2} \mathrm{M}$, and then diluted in HBSS to the final concentrations indicated. Rolipram, a gift from Schering (Berlin, Germany), was first dissolved in dimethyl sulphoxide (DMSO), which resulted in a stock of $10^{-1} \mathrm{M}$. Phosphate-buffered saline (PBS) containing $2.5 \%(\mathrm{v} / \mathrm{v})$ of a heat-inactivated bovine albumin solution (200 $\mathrm{g} \cdot \mathrm{L}^{-1}$ with $1 \mathrm{~g} \cdot \mathrm{L}^{-1}$ sodium azide; Organon Teknika, Boxtel, The Netherlands) was used as a washing solution. Human AB-serum was obtained from the Laboratory of The Netherlands Red Cross Blood
Bank (Groningen, The Netherlands). Formaldehyde fixative (37\%; Merck, Darmstadt, Germany) was diluted in PBS to acquire a final concentration of $0.1 \%$.

\section{Monoclonal antibodies}

Antibodies against CD11b, L-selectin (Leu8) and fluorescein isothiocyanate-conjugated goat anti-mouse immunoglobulin (GAM-FITC) were purchased from Becton Dickinson (Mountain View, CA, USA). Mouse isotype control antibodies (immunoglobulin $2 \mathrm{a}(\mathrm{IgG} 2 \mathrm{a})$ ) were supplied by the Central Laboratory of The Netherlands Red Cross Blood Transfusion Service (Amsterdam, The Netherlands).

\section{Cell stimulation}

In order to investigate whether the effects of rolipram on receptor expression could be related to an increase in intracellular cAMP, inhibition by other cAMP elevating agents on PAF-induced adhesion receptor expression was also tested. This was done in a number of experiments by incubating cells in the presence of buffer or $10^{-8}, 10^{-7}, 10^{-6}$, and $10^{-5} \mathrm{M}$ of $\mathrm{PGE}_{2}$ or isoproterenol. In addition, the effect of preincubation with $10^{-5}, 10^{-4}, 10^{-3}$ and $10^{-2} \mathrm{M}$ of dibutyryl cAMP was studied. Concentration curves were drawn for each separate experiment. For rolipram, the concentration that induces $20 \%$ inhibition (IC20) was determined from these curves.

Cells were stimulated and labelled in whole blood, according to a slightly modified procedure described previously [31]. Briefly, ethylenediamine tetra-acetic acid (EDTA)-anticoagulated blood was washed twice with excess PBS at room temperature. In order to determine in vivo $\mathrm{CD} 11 \mathrm{~b}$ expression as a control, some blood samples were fixed with $0.1 \%$ formaldehyde directly after collection, before washing. After washing, the cells were resuspended in PBS to reconstitute the original volume. From this suspension, $100 \mu \mathrm{L}$ samples were stimulated with buffer or PAF for $15 \mathrm{~min}$ at $37^{\circ} \mathrm{C}$, in a total volume of $500 \mu \mathrm{L}$. PAF was used, since it is a stimulus for neutrophils as well as eosinophils, and may play a role in asthmatic inflammation [32].

The effects of the receptor-dependent inhibitors, isoproterenol and $\mathrm{PGE}_{2}$, were tested by simultaneous incubation with PAF. To allow intracellular diffusion, the inhibitory effect of dibutyryl cAMP was studied by preincubation for $15 \mathrm{~min}$ at $37^{\circ} \mathrm{C}$ before incubation with PAF. The effect of rolipram was also tested by preincubation for $15 \mathrm{~min}$, and subsequent incubation with PAF with or without $\mathrm{PGE}_{2}$ or isoproterenol. The incubations were stopped by adding $2 \mathrm{~mL}$ of ice-cold washing buffer. After centrifugation at $1,000 \times \mathrm{g}$ for $2 \mathrm{~min}$, the cells were fixed with $0.1 \%$ formaldehyde for $10 \mathrm{~min}$ and stained for flow cytometry.

Effects of rolipram in combination with $P G E_{2}$ or isoproterenol

PDE inhibitors, such as rolipram, may act synergistically with receptor-dependent activators of the adenylyl cyclase system in vitro [23-25]. Therefore, the effect 
of rolipram was studied in the presence of a receptorcoupled stimulus of the adenylyl cyclase system. For this purpose, $10^{-8} \mathrm{M}$ of rolipram was used, because this concentration induced little direct inhibition of PAFinduced receptor expression. Whole blood was preincubated with rolipram, and subsequent PAF-stimulation was performed in the presence or absence of $0.5 \times 10^{-8}$ $\mathrm{M}$ isoproterenol or $10^{-8} \mathrm{M} \mathrm{PGE}_{2}$. These concentrations of isoproterenol and $\mathrm{PGE}_{2}$ result in approximately half of the maximum inhibition of the PAF response, as estimated from the concentration curves in figure 1a and b. Since the eosinophil was the main cell type of interest, the curves for eosinophils were used for this purpose.

\section{Immunofluorescence staining}

After fixation, the cells were labelled for $15 \mathrm{~min}$ at room temperature with $10 \mu \mathrm{L}$ of anti-CD11b, anti-Lselectin or control antibodies of the same mouse isotype
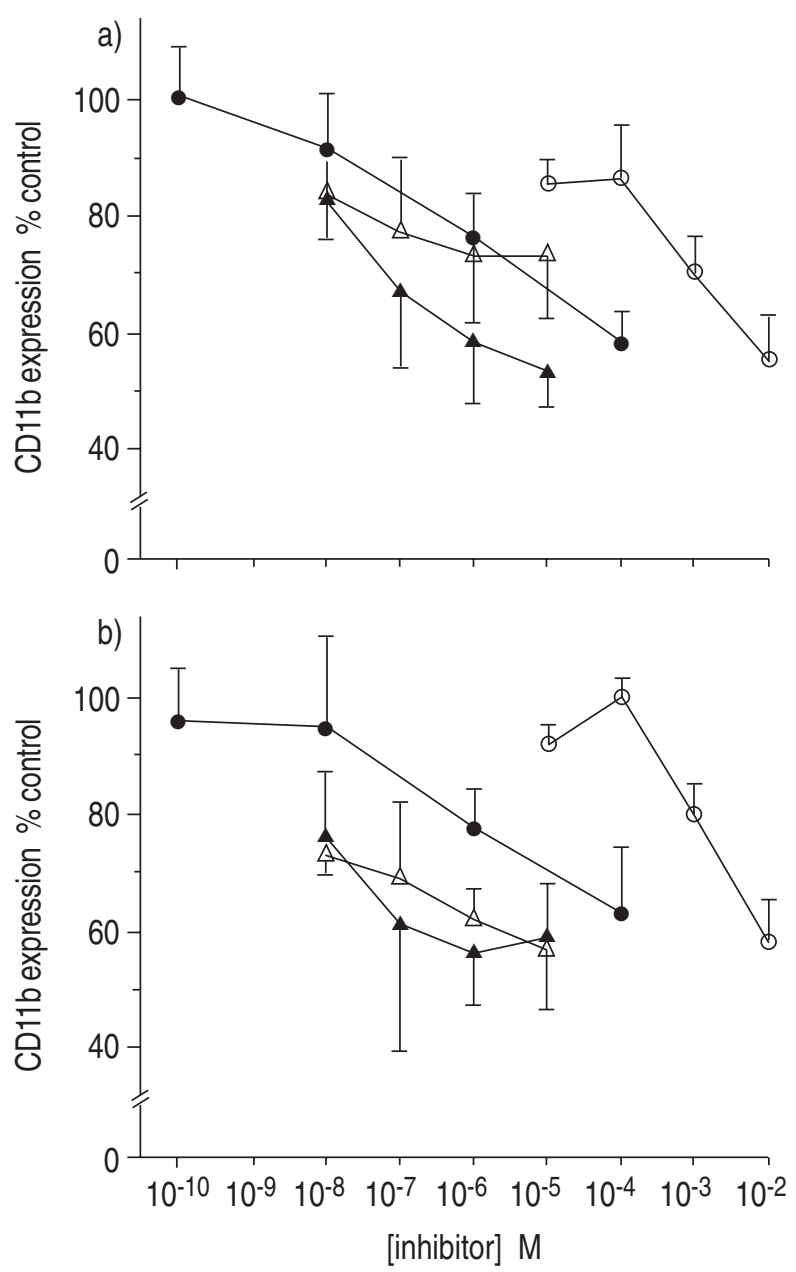

Fig. 1. - Effect of different concentrations of prostaglandin $\mathrm{E}_{2}$ $\left(\mathrm{PGE}_{2}\right)(\mathrm{n}=3)$, isoproterenol $(\mathrm{n}=4)$, dibutyryl cyclic adenosine monophosphate $(\mathrm{cAMP})(\mathrm{n}=3)$ or rolipram $(\mathrm{n}=5)$ on the PAF-induced $\left(10^{-7} \mathrm{M}\right)$ CD11b expression of: a) neutrophils; and b) eosinophils, in whole blood. Results are presented as a percentage of the response with PAF in the absence of cAMP modulating agents (\% of control). Data are presented as mean \pm SEM. No effects of cAMP modulators were seen in the absence of PAF (not shown). $\_-$: $\mathrm{PGE}_{2} ;-\Delta-$ : isoproterenol; —— : rolipram; —O- : dibutyryl cAMP. PAF: plateletactivating factor.
(IgG2a). This was done in the presence of $10 \mu \mathrm{L}$ of diluted human AB-serum (20\%), in order to prevent nonspecific binding of antibody. After lysis of red blood cells with lysis buffer $\left(155 \mathrm{mmol} \cdot \mathrm{L}^{-1} \mathrm{NH}_{4} \mathrm{Cl}, 10 \mathrm{mmol} \cdot \mathrm{L}^{-1}\right.$ $\mathrm{KHCO}_{3}, 0.1 \mathrm{mmol} \cdot \mathrm{L}^{-1}$ EDTA), each sample was incubated with $50 \mu \mathrm{L}$ of GAM-FITC (20\% v/v in washing buffer), in the presence of $5 \% \mathrm{AB}$-serum, for 15 min at room temperature in the dark. After washing, the cells were resuspended in washing buffer and kept at $4^{\circ} \mathrm{C}$ in the dark until analysed. Flow cytometric analysis was performed within $4 \mathrm{~h}$ after staining.

\section{Flow cytometry}

Flow cytometric measurements were performed with a fluorescence-activated cell sorter (Becton-Dickinson FACStar). Fluorescence gain was standardized with Quick Cell 3 beads (Flow Cytometry Standards Co., San Juan, Puerto Rico). Neutrophils and eosinophils were discriminated by means of depolarized orthogonal light scattering, as described previously [28, 31, 33]. In samples with low eosinophil numbers, the threshold for depolarized light scatter was increased in order to exclude neutrophils from the 10,000 events that were collected. In this way, higher numbers of eosinophils could be obtained during data collection. Data on neutrophils were collected by a second measurement of the same sample using a normal threshold. Evaluation of mean specific fluorescence on neutrophils and eosinophils was performed using a personal computer (Hewlett Packard) and the Lysis program (Becton Dickinson). During evaluation, neutrophils and eosinophils were gated based on forward scatter/sideward scatter (FSC/SSC), and further discriminated by SSC and depolarized light scattering.

Expression of specific receptors is presented as mean fluorescence intensity (MFI) ( \pm SEM), after subtraction of the fluorescence with control antibody. The percentage control in the presence of a cAMP-elevating agent was calculated as percentage of the response by PAF alone.

\section{Statistical analysis}

Differences between various incubation conditions were evaluated using Student's t-test for paired data. A p-value less than 0.05 was considered significant.

\section{Results}

\section{Effect of PAF on receptor expression}

A concentration of $10^{-7}$ M PAF did not cause maximal CD11b expression on neutrophils and eosinophils, since $10^{-6} \mathrm{M}$ was able to induce an additional increase (fig. 2a). In order to ensure sensitivity to the effects of the inhibitory compounds, a submaximal concentration of PAF was selected. Since $10^{-6} \mathrm{M}$ induced more CD11b expression than $10^{-7} \mathrm{M}$ (fig. 2a), the latter concentration 

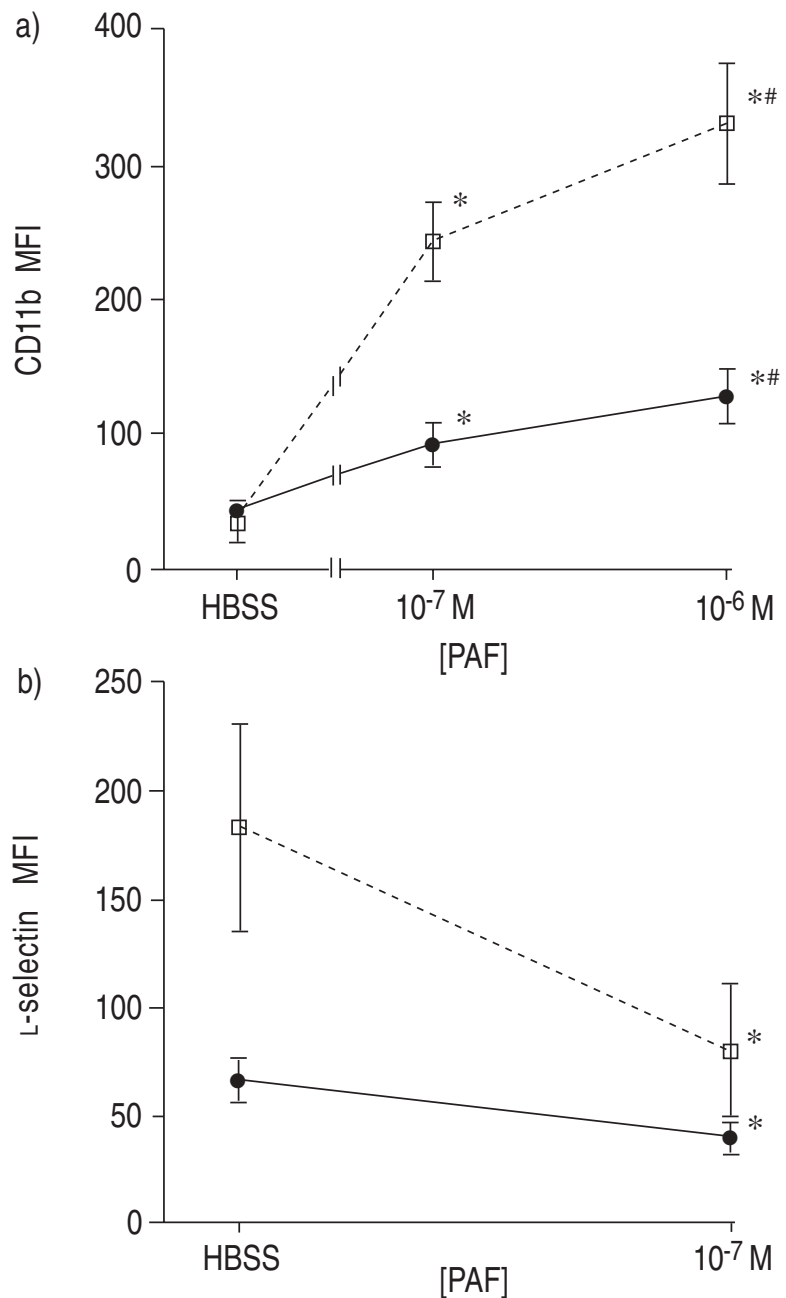

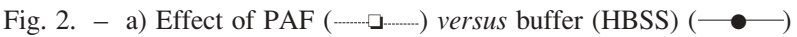
on $\mathrm{CD} 11 \mathrm{~b}$ expression of neutrophils and eosinophils. Whole blood was incubated with $10^{-7}$ or $10^{-6} \mathrm{M}$ of PAF for $15 \mathrm{~min}$ at $37^{\circ} \mathrm{C}$. Subsequently, CD11b expression was determined by flow cytometry after labelling with anti-CD11b and GAM-FITC, as described in Materials and methods. Results are presented as mean $\pm \operatorname{SEM}(n=7)$. b) Similarly, the effect of $10^{-7} \mathrm{M}$ of PAF on L-selectin expression $(n=8)$ was determined. PAF: platelet-activating factor; HBSS: Hank's balanced salt solution; GAM-FITC: fluorescein isothiocyanate conjugated goat anti-mouse immunoglobulin; MFI: mean fluorescence intensity. *: $\mathrm{p}<0.05$ vs HBSS, Student's paired t-test; \#: $\mathrm{p}<0.05$ vs $10^{-7} \mathrm{M}$ PAF, Student's paired t-test.

was chosen. The relative increases of CD11b on neutrophils and eosinophils induced by this concentration of PAF were 615 and $110 \%$, respectively. In addition, a significant decrease $(\mathrm{p}<0.05)$ of $\mathrm{L}$-selectin on neutrophils $(-57 \%)$ and eosinophils $(-41 \%)$ could be observed after incubation with this concentration of PAF (fig. 2b). For both receptors, the effects of PAF were more marked on neutrophils than on eosinophils. CD11b expressions in samples incubated with HBSS were not significantly different from directly fixed blood samples. CD11b expression on neutrophils and eosinophils in directly fixed blood samples was $37 \pm 9$ and $61 \pm 8(n=7)$, respectively. After incubation with $\mathrm{HBSS}$ for $15 \mathrm{~min}$ at $37^{\circ} \mathrm{C}$, these values were $36 \pm 9$ and $59 \pm 6$, respectively. This indicates that no activation was induced by handling of the cells.
Effect of single cAMP modulators on CD11b expression

From separate experiments with $\mathrm{PGE}_{2}$, isoproterenol, dibutyryl cAMP and rolipram concentration curves were drawn. In most experiments, the maximum inhibition observed was less then $50 \%$.

As shown in figure $1 \mathrm{a}$ and $\mathrm{b}, \mathrm{PGE}_{2}$ was the most potent inhibitor of PAF-induced CD11b expression on neutrophils and eosinophils, reducing the PAF responses by $47 \pm 6$ and $41 \pm 9 \%$, respectively $(n=3)$. Significant $(\mathrm{p}<0.05)$ inhibition was observed at concentrations of $\mathrm{PGE}_{2}$ higher than $10^{-6} \mathrm{M}$.

Isoproterenol also significantly reduced PAF-induced CD11b expression $(p<0.05)$. However, in neutrophils, it was less potent than $\mathrm{PGE}_{2}$, and $10^{-5} \mathrm{M}$ isoproterenol resulted in a maximum inhibition of only $27 \pm 11 \%$ (fig. $2 a)$. The curve for neutrophils was flatter than the curve for eosinophils. In eosinophils, the maximum inhibition of the response by isoproterenol was comparable to the inhibition by $\mathrm{PGE}_{2}(43 \pm 11 \%)$. The difference between neutrophils and eosinophils for the maximum effect of isoproterenol in this limited number of experiments was, however, not significant. Dibutyryl cAMP was a much less potent inhibitor of the PAF-induced CD11b expression than $\mathrm{PGE}_{2}$, as the concentration curve was shifted to the right (fig. 1a and b). The maximal inhibition of neutrophils and eosinophils was comparable.

The PAF-induced CD11b expression on neutrophils and eosinophils was significantly inhibited by rolipram (fig. 1a and $b ; n=5$ ). Although there was a trend for inhibition at $10^{-8} \mathrm{M}$ rolipram, statistical significance was found at $10^{-6} \mathrm{M}$ for both cell types. With the highest concentration of rolipram, $10^{-4} \mathrm{M}$, the inhibition of CD11b expression on neutrophils and eosinophils was $41 \pm 5$ and $37 \pm 11 \%$, respectively. Since $50 \%$ inhibition was not achieved, the concentration inducing 50\% inhibition (IC50) could not be determined, and the IC20 was determined instead. The IC20s of rolipram for inhibition of CD11b expression were $10 \pm 14 \mu \mathrm{M}$ for neutrophils and $0.2 \pm 0.4 \mu \mathrm{M}$ for eosinophils.

\section{Effect of single cAMP modulators on L-selectin expres- sion}

The PAF-induced L-selectin shedding on neutrophils and eosinophils was also inhibited by $\mathrm{PGE}_{2}$, isoproterenol, dibutyryl cAMP and rolipram.

$\mathrm{PGE}_{2}$ was the most potent inhibitor of L-selectin shedding from neutrophils (fig. 3a). The maximum inhibition observed at $10^{-5} \mathrm{M}$ was $52 \pm 3 \%$ for neutrophils and $37 \pm 11 \%$ for eosinophils (fig. $3 a$ and $b$ ).

The maximum inhibition of PAF-induced L-selectin shedding from neutrophils by $10^{-5} \mathrm{M}$ of isoproterenol was only $22 \pm 7 \%$ (fig. 3a). For eosinophils, however, it was comparable to the mean maximum inhibition by $\mathrm{PGE}_{2}, 34 \pm 24 \%$ (fig. 3b). The difference between neutrophils and eosinophils was not statistically significant in these experiments.

Again, dibutyryl cAMP was the least potent inhibitor of PAF-induced L-selectin shedding (fig. 3a and $b$ ). Maximum inhibition of L-selectin shedding from neutrophils and eosinophils was $37 \pm 10$ and $29 \pm 6 \%$. Remarkably, the curve for neutrophils was much steeper than the curve for eosinophils. 

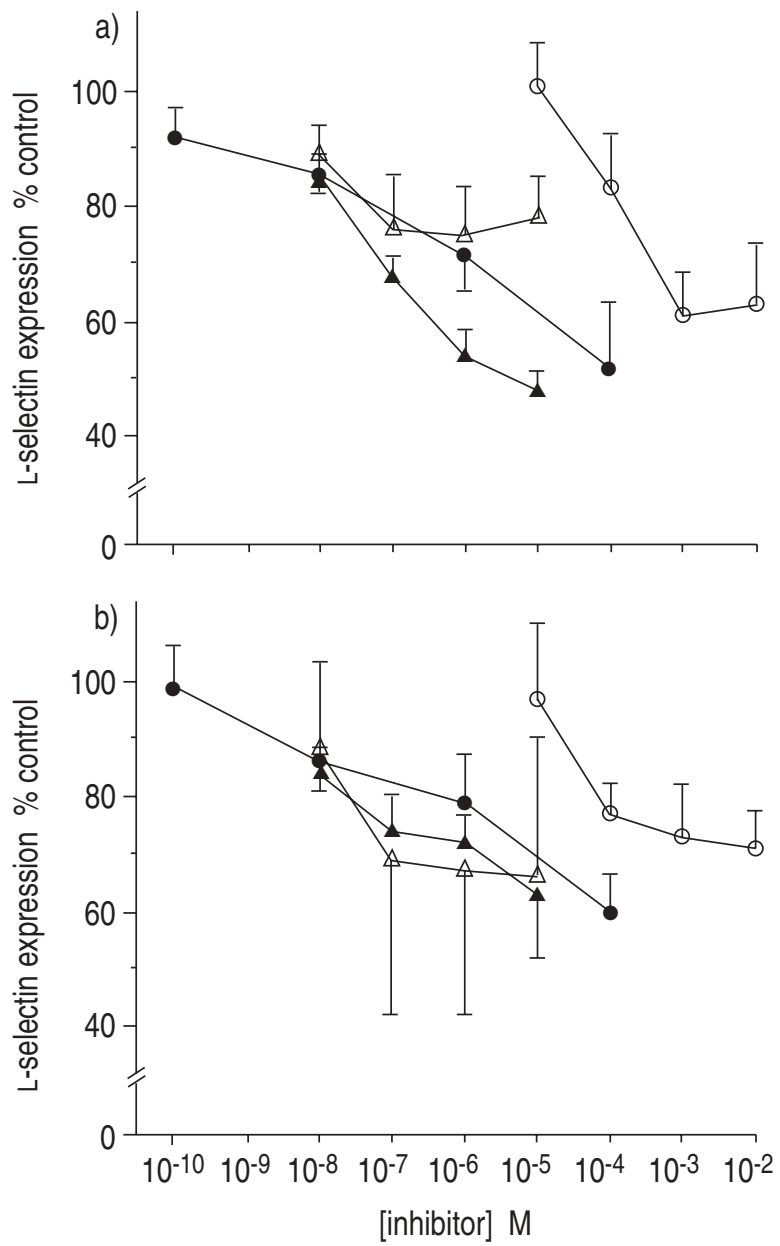

Fig. 3. - Effect of different concentrations of prostaglandin $\mathrm{E}_{2}\left(\mathrm{PGE}_{2}\right)$ $(n=3)$, isoproterenol $(n=4)$, dibutyryl cyclic adenosine monophosphate $(\mathrm{cAMP})(\mathrm{n}=3)$ or rolipram $(\mathrm{n}=5)$ on the PAF-induced $\left(10^{-7} \mathrm{M}\right)$ L-selectin expression of: a) neutrophils; and b) eosinophils, in whole blood. Results are presented as a percentage of the response with PAF in the absence of cAMP modulating agents (\% of control). Data are presented as mean \pm SEM. No effects of cAMP modulators were seen in the absence of PAF (not shown). $\_-$PGE $_{2}:-\Delta-$ : isoproterenol; —— : rolipram; ——— : dibutyryl cAMP. PAF: plateletactivating factor.

Small but statistically significant inhibition of PAFinduced L-selectin shedding from neutrophils and eosinophils was found with $10^{-10}$ and $10^{-8} \mathrm{M}$ of rolipram, respectively. Maximum inhibition of $48 \pm 11$ and $41 \pm 6 \%$, respectively, was observed with $10^{-4} \mathrm{M}$ rolipram. This was comparable to the maximum inhibitions found with $\mathrm{PGE}_{2}$. The IC20s for rolipram on PAF-induced L-selectin shedding from neutrophils and eosinophils were $15 \pm$ 21 and $0.2 \pm 0.4 \mu \mathrm{M}$, respectively.

As shown in figure $4 \mathrm{a}$, the combination of rolipram and isoproterenol or $\mathrm{PGE}_{2}$ induced a statistically significantly $(\mathrm{p}<0.05)$ greater inhibition of PAF-induced CD11b expression than each inhibitor alone $(n=7)$. This was observed for neutrophils as well as eosinophils. When the inhibition, calculated as 100 - \% of control, with the combination of rolipram and isoproterenol or $\mathrm{PGE}_{2}$ was compared with the sum of the inhibition by each agent separately, no differences were found. For instance, the sum of the inhibition of neutrophil CD11b expression by rolipram and isoproterenol was $40 \pm 11 \%$. When rolipram and isoproterenol were combined in the
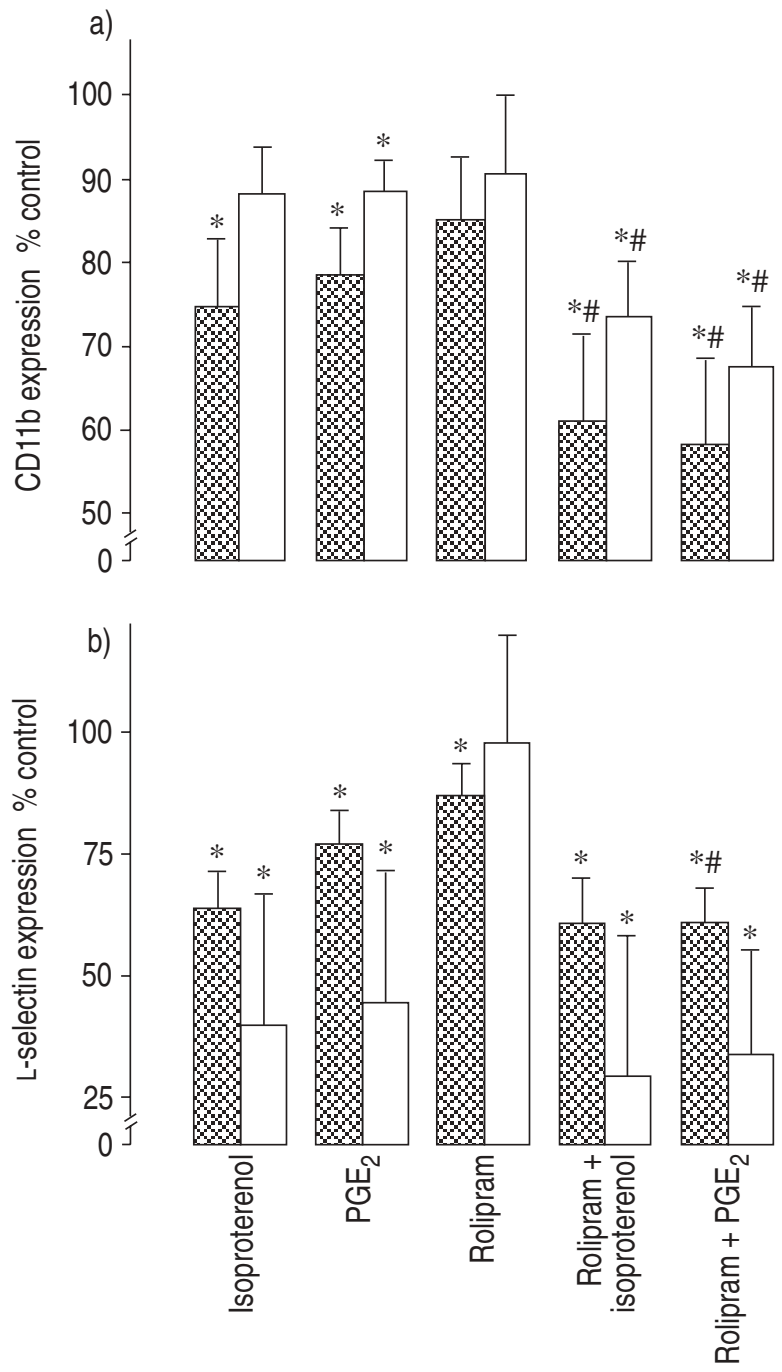

Fig. 4. - Effect of isoproterenol $\left(0.5 \times 10^{-8} \mathrm{M}\right)$, prostaglandin $\mathrm{E}_{2}$ $\left(\mathrm{PGE}_{2}\right)\left(10^{-8} \mathrm{M}\right)$, rolipram $\left(10^{-8} \mathrm{M}\right)$ or combinations of these agents on: a) CD11b expression; and b) L-selectin expression of PAF-stimulated neutrophils or eosinophils $(n=7)$. Results are expressed as a percentage of the response induced by PAF in the absence of inhibitors; a) PAF increased CD11b expression from $32 \pm 9$ to $312 \pm 46$ for neutrophils and from $47 \pm 6$ to $148 \pm 20$ for eosinophils (MFI mean \pm SEM). b) PAF decreased L-selectin expression from $177 \pm 18$ to $72 \pm 10$ for neutrophils and from $66 \pm 9$ to $39 \pm 6$ for eosinophils (MFI mean \pm SEM). No effects of inhibitors were seen in the absence of PAF (not shown). $\quad \vdots:$ : neutrophils; $\square$ : eosinophils. For definitions see legend to figure 1. *: $\mathrm{p}<0.05$ vs PAF without inhibitor, Student's paired t-test; \#: $\mathrm{p}<0.05$ vs corresponding sample without rolipram, Student's paired t-test.

same experiment, $39 \pm 10 \%$ inhibition of the relative increase in CD11b was found. This indicates an additive response of rolipram and isoproterenol. Similar results were observed for $\mathrm{PGE}_{2}$.

In the same experiments, the effect of rolipram and isoproterenol or $\mathrm{PGE}_{2}$ was investigated on the PAFinduced decrease of L-selectin (fig. 4b). However, a significant effect of combining inhibitors was only found for rolipram and $\mathrm{PGE}_{2}$ on neutrophils, and not on eosinophils. As had been found for CD11b, the sum of the single inhibitions by rolipram and $\mathrm{PGE}_{2}$ was not significantly different from the inhibition observed when the agents were combined in the same sample. Again, this indicates an additive, but not synergistic, inhibition. 
Remarkably, the combination of rolipram and isoproterenol or $\mathrm{PGE}_{2}$ inhibited the L-selectin shedding from eosinophils by $71 \pm 28$ and $67 \pm 21 \%$, respectively. Although a trend could be observed, the additive effect of rolipram and isoproterenol on L-selectin was not significant.

\section{Discussion}

The present study demonstrates that rolipram inhibits PAF-induced CD11b increase and a concomitant Lselectin decrease on human neutrophils and eosinophils. The experiments have been performed in unseparated whole blood samples, so that interactions between cell types were similar to the in vivo situation, and less in vitro activation of granulocytes was induced by isolation procedures $[29,30]$. An additional, but not synergistic, inhibitory effect on PAF-induced receptor expression was observed when rolipram was followed by an activator of the adenylyl cyclase.

NeELEY et al. [12] reported that $10^{-7} \mathrm{M}$ PAF caused mean increases of CD11b expression of 35 and $43 \%$ in neutrophils and eosinophils, respectively. In the present study, these increases were as high as $615 \%$ in neutrophils and $110 \%$ in eosinophils. Similarly, the concomitant decrease of L-selectin expression on neutrophils was higher in the present study. Moreover, NEELEY et al. [12] observed that $10^{-8} \mathrm{M}$ PAF caused changes in eosinophil CD11b expression similar to those caused by $10^{-7} \mathrm{M}$ of PAF, suggesting a maximal effect at $10^{-8} \mathrm{M}$. In the present study, the CD11b expression continued to increase with $10^{-6} \mathrm{M}$ of PAF. The differences in the magnitude of the response to PAF may be due to the fact that NEELEY et al. [12] purified cells using several washing steps, thereby inducing a higher basal CD11b expression [28-30]. Basal CD11b expression of neutrophils and eosinophils in the present study was not changed by incubation, as shown by the fact that no significant differences were found between buffer-incubated cells and directly fixed cells.

Adhesion and transmigration of granulocytes is not only regulated by receptor number but also by receptor avidity [34, 35]. DERIAN et al. [27] reported approximately $80 \%$ inhibition of $\mathrm{N}$-formyl-methionyl-leucylphenylalanine (fMLP)-induced neutrophil adherence to endothelial cells by $1-10 \mu \mathrm{M}$ rolipram. CD11b expression was also shown to be inhibited, but this was not analysed quantitatively. In the present study, however, it was shown that this inhibition does not exceed 50\%, even with high concentrations of rolipram. When $1 \mu \mathrm{M}$ rolipram was used, the inhibition of CD11b expression was only $20-25 \%$ for neutrophils and eosinophils. Therefore, it is very likely that rolipram and other cAMP modulators also inhibit receptor avidity as well as CD11b receptor number. However, stimulus specificity or additional actions on endothelial cells may also be involved in the disparity between the effects of rolipram on the expression of adhesion molecules and adhesion. Moreover, enlarging the magnitude of the response by using whole blood cells, as discussed above, may decrease the potency of inhibitors.

Although there was a trend for inhibition of CD11b expression at low concentrations of rolipram, significant inhibition was found at $10^{-6}$ and $10^{-4} \mathrm{M}$ rolipram.
This is in accordance with the study by NiELSON et al. [23], in which significant inhibition of the respiratory burst of polymorphonuclear leucocytes was found at concentrations of rolipram greater than $10^{-6} \mathrm{M}$. The degree of inhibition observed at the highest concentrations is also similar to that observed for inhibition of respiratory burst in human neutrophils [23] and eosinophils [36]. DENT and co-workers [36] have reported an IC50 of approximately $40 \mu \mathrm{M}$ for inhibition of opsonized zymosan-induced superoxide production in eosinophils. From the curves shown in their paper, we estimated an $\mathrm{IC}_{20}$ of $0.1 \mu \mathrm{M}$. The IC20 for inhibition of PAFinduced adhesion receptor expression in the present study was $0.2 \mu \mathrm{M}$. Thus, inhibition of respiratory burst and adhesion receptor expression may occur at similar concentrations of rolipram.

L-selectin decrease was also observed to be inhibited by rolipram. Interestingly, significant inhibition of Lselectin shedding was found with concentrations of rolipram as low as $10^{-8} \mathrm{M}$. Furthermore, a combination of $10^{-8} \mathrm{M}$ rolipram and $0.5 \times 10^{-8} \mathrm{M}$ isoproterenol or $10^{-8} \mathrm{M}$ $\mathrm{PGE}_{2}$ inhibited L-selectin shedding on eosinophils by $70 \%$. Therefore, the initial rolling step in eosinophil infiltration may be equally or more sensitive to inhibition by cAMP modulators than CD11b-mediated adhesion. PDE inhibitors may, therefore, be more successful when applied systemically, thereby attenuating rolling of eosinophils in peripheral blood. This may explain why orally administered theophylline attenuates eosinophil infiltration in asthmatic patients, as has been described recently [37].

Rolipram has been shown to increase intracellular cAMP in neutrophils and eosinophils via inhibition of a cAMP-specific, cyclic guanosine monophosphate (cGMP)-insensitive PDE $[20,23]$. Therefore, the inhibition of PAF-induced CD11b and L-selectin expression, described in the present study, is likely to be due to a rise in intracellular cAMP. This is further suggested by the observation that stimulation of adenylyl cyclase with $\mathrm{PGE}_{2}$ or isoproterenol also inhibits changes in receptor expression. Moreover, the cAMP analogue, dibutyryl cAMP, was able to inhibit both the increase in CD11b and the decrease in L-selectin on neutrophils and eosinophils. About $45 \%$ inhibition of PAF-induced CD11b expression on neutrophils was observed at a concentration of $10^{-2} \mathrm{M}$ dibutyryl cAMP. This is similar to the percentage found in a study by WoLLNER et al. [38], in which $58 \%$ inhibition of the fMLP-induced CD11b expression on neutrophils was observed in the presence of the same concentration of dibutyryl cAMP. In contrast, BROwN et al. [39] did not observe an effect of dibutyryl cAMP on neutrophil CD11b expression. The reason for the different outcome of this latter study is unknown.

Inhibition by cAMP-elevating agents has been reported for several $\mathrm{Ca}^{2+}$-dependent granulocyte functions, including leukotriene and prostaglandin production, respiratory burst and degranulation [20, 22, 23, 25, 40]. This inhibition may be mediated by binding of cAMP to protein kinase A (PKA) and subsequent subunit dissociation. This step has been shown to uncouple heterologous receptors from phospholipase C (PLC), resulting in the inhibition of agonist-dependent increases in intracellular free $\mathrm{Ca}^{2+}$ concentrations $[41,42]$. In the present study, PAF was used as an agonist, and it has been 
found that PAF acts, at least partly, via the PLC pathway $[43,44]$. This pathway results in a subsequent transient rise in intracellular $\mathrm{Ca}^{2+}$, which can be attenuated by rolipram [24]. A rise in intracellular $\mathrm{Ca}^{2+}$ has also been shown to play a role in upregulation of CD11b expression $[45,46]$. Thus, the inhibition of PAF-induced CD11b increase by rolipram and other cAMP-elevating agonists may be mediated by downmodulation of the capacity of PAF to activate PLC. The observation that changes in CD11b and L-selectin are concomitantly modulated by PAF and inhibited by cAMP-elevating agents suggests that both receptors are, at least partly, under control of the same $\mathrm{Ca}^{2+}$-dependent transduction pathway.

A synergistic inhibition of rolipram and isoproterenol or $\mathrm{PGE}_{2}$ was expected because of potentiation of cAMP production found in previous studies [24]. In addition, it has been shown that rolipram and isoproterenol synergistically inhibit $\mathrm{Ca}^{2+}$ ionophore-induced chemiluminescence, although this was dependent upon the time at which the response was measured [23]. A cumulative, instead of a synergistic, effect with respect to PAFinduced adhesion receptor expression was observed in the present study. There are various possible explanations for the lack of synergy. Firstly, a mechanism other than increase of cAMP may be involved, thereby masking synergy of rolipram with isoproterenol or $\mathrm{PGE}_{2}$. DERIAN et al. [27] have shown that rolipram and endogenously produced adenosine work in concert to affect neutrophil adhesion. Inhibition of CD11b expression by adenosine on fMLP-stimulated neutrophils has been reported [38]. As in the present study, a maximum inhibition of about $50 \%$ could be reached. It was concluded that adenosine exerted this effect via A2 receptors and possibly via activation of adenylyl cyclase. A2 receptors are also involved in inhibition of eosinophils [47]. CRONSTEIN et al. [48], however, have proposed that inhibition by adenosine is mediated not only by an increase in cAMP but also via an alternative mechanism of action. Secondly, rolipram may potentiate the cAMP production, as has been described previously [24], but the amount of intracellular cAMP may be far more than is needed for maximal inhibition. This is supported by the demonstration that rolipram and the $\beta$-adrenoceptor agonist, albuterol, exhibit synergy in elevating intracellular cAMP in human eosinophils, but do not act synergistically in suppressing respiratory burst [36]. These hypotheses could not be tested in the present study, since a mixture of different cell types were used. Isolated neutrophils and eosinophils will probably not be similar to the cells in whole blood. The cumulative increased inhibition observed in the presence of isoproterenol or $\mathrm{PGE}_{2}$ may be of relevance in vivo. The concentration of prostaglandins, for instance, has been shown to be increased in bronchoalveolar lavage after instillation of ragweed allergen extracts in allergic asthmatics [49].

In conclusion, we have shown that rolipram inhibits CD11b increase and L-selectin shedding of platelet-activating factor-stimulated neutrophils and eosinophils in whole blood. With respect to $\mathrm{CD} 11 \mathrm{~b}$ expression, the inhibition by rolipram alone or in combination with isoproterenol or prostaglandin $\mathrm{E}_{2}$ did not exceed $50 \%$. Inhibition of shedding of L-selectin from eosinophils, but not neutrophils, was found to be $70 \%$ with a combination of low concentrations of rolipram and prostaglandin
$\mathrm{E}_{2}$ or isoproterenol. Inhibition by type IV phosphodiesterase inhibitors of the initial rolling of eosinophils may, therefore, be a relevant subject for further investigation.

\section{References}

1. de Monchy JGR, Kauffman HF, Venge P, et al. Bronchoalveolar eosinophilia during allergen-induced late asthmatic reactions. Am Rev Respir Dis 1985; 131: 373-376.

2. Hansel T, Walker C. The migration of eosinophils into the sputum of asthmatics: the role of adhesion molecules. Clin Exp Allergy 1992; 22: 345-356.

3. Tate RM, Repine JE. Neutrophils and the adult respiratory distress syndrome. Am Rev Respir Dis 1983; 28: 552-559.

4. Bruijnzeel PLB. Contribution of eosinophil-derived mediators in asthma. Int Arch Allergy Appl Immunol 1989; 90: 57-63.

5. Weiss SJ. Tissue destruction by neutrophils. $N$ Engl $J$ Med 1989; 320: 365-376.

6. Springer TA. Adhesion receptors of the immune system. Nature 1990; 346: 425-434.

7. Bochner BS, Schleimer RP. The role of adhesion molecules in human eosinophil and basophil recruitment. $J$ Allergy Clin Immunol 1994; 94: 427-438.

8. Lawrence MB, Springer TA. Leukocytes roll on a selectin at physiologic flow rates: distinction from and prerequisite for adhesion through integrins. Cell 1991; 65: 859-873.

9. von Andrian UH, Chambers JD, McEvoy LM, Bargatze RF, Arfors KE, Butcher EC. Two-step model of leukocyte-endothelial cell interaction in inflammation: distinct roles for LECAM-1 and the leukocyte beta ${ }_{2}$-integrins in vivo. Proc Natl Acad Sci USA 1991; 88: 7538-7542.

10. O'Shea J, Brown EJ, Seligmann BE, Metcalf JA, Frank M, Gallin JI. Evidence for distinct intracellular pools of receptors for $\mathrm{C} 3 \mathrm{~b}$ and $\mathrm{C} 3 \mathrm{bi}$ in human neutrophils. $J$ Immunol 1985; 134: 2580-2587.

11. Zimmerman GA, McIntyre TM, Mehra M, Prescott SM. Endothelial cell-associated platelet-activating factor: a novel mechanism for signalling intercellular adhesion. J Cell Biol 1990; 110: 529-540.

12. Neeley SP, Hamann KJ, White SR, Baranowski SL, Burch RA, Leff AR. Selective regulation of expression of surface adhesion molecules, Mac-1, L-selectin and VLA-4, on human eosinophils and neutrophils. Am $J$ Respir Cell Mol Biol 1993; 8: 633-639.

13. Walker C, Rihs S, Braun RK, Betz S, Bruijnzeel PLB. Increased expression of $\mathrm{CD} 11 \mathrm{~b}$ and functional changes in eosinophils after migration across endothelial cell monolayers. J Immunol 1993; 150: 4061-4071.

14. Mengelers HJ, Maikoe T, Hooibrink B, et al. Downmodulation of L-selectin expression on eosinophils recovered from bronchoalveolar lavage fluid after allergen provocation. Clin Exp Allergy 1993; 23: 196-204.

15. Georas SN, Liu MC, Newman W, Beall LD, Stealey BA, Bochner BS. Altered adhesion molecule expression and endothelial cell activation accompany the recruitment of the human granulocytes to the lung after segmental antigen challenge. Am J Respir Cell Mol Biol 1992; 7: 261-269.

16. Newsholme SJ, Schwartz L. cAMP-specific phosphodiesterase inhibitor, rolipram, reduces eosinophil infiltration evoked by leukotrienes or by histamine in guinea-pig conjunctiva. Inflammation 1993; 17: 25-31.

17. Underwood DC, Osborn R, Novak LB, et al. Inhibition 
of antigen-induced bronchoconstriction and eosinophil infiltration in the guinea-pig by the cyclic AMP-specific phosphodiesterase inhibitor, rolipram. J Pharmacol Exp Ther 1993; 266: 306-313.

18. Griswold DE, Webb EF, Breton J, White JR, Marshall PJ, Torphy TJ. Effect of selective phosphodiesterase type IV inhibitor, rolipram, on fluid and cellular phases of inflammatory response. Inflammation 1993; 17: 333-344.

19. Torphy TJ, Undem BJ. Phosphodiesterase inhibitors: new opportunities for the treatment of asthma. Thorax 1991; 46: 512-523.

20. Dent G, Giembycz MA, Rabe KF, Barnes PJ. Inhibition of eosinophil cyclic nucleotide PDE activity and opsonised zymosan-stimulated respiratory burst by "type IV"selective PDE inhibitors. Br J Pharmacol 1991; 103: 1339-1346.

21. Polson JB, Krzanowski J, Szentivanyi A. Inhibition of a high affinity cyclic AMP phosphodiesterase and relaxation of canine tracheal smooth muscle. Biochem Pharmacol 1983; 31: 3403-3406.

22. Zurier RB, Weismann G, Hoffstein S. Mechanisms of lysosomal enzyme release from human leukocytes. II. Effects of cAMP and cGMP, autonomic agonists, and agents which affect microtubule function. J Clin Invest 1974; 53: 297-309.

23. Nielson CP, Vestal RE, Sturm RJ, Heaslip R. Effects of selective phosphodiesterase inhibitors on the polymorphonuclear leukocyte respiratory burst. J Allergy Clin Immunol 1990; 86: 801-808.

24. Souness JE, Carter CM, Diocee BK, Hassall GA, Wood LJ, Turner NC. Characterization of guinea-pig eosinophil phosphodiesterase activity: assessment of its involvement in regulating superoxide generation. Biochem Pharmacol 1991; 42: 937-945.

25. Kita H, Abu-Ghazaleh RI, Gleich GJ, Abraham RT. Regulation of Ig-induced eosinophil degranulation by adenosine 3',5'-cyclic monophosphate. J Immunol 1991; 146: 2712-2718.

26. Barnes PJ. Cyclic nucleotides and phosphodiesterases and airway function. Eur Respir $J$ 1995; 8: 457-462.

27. Derian CK, Santulli RJ, Rao PE, Solomon HF, Barrett JA. Inhibition of chemotactic peptide-induced neutrophil adhesion to vascular endothelium by cAMP modulators. J Immunol 1995; 154: 308-317.

28. Berends C, Dijkhuizen B, de Monchy JGR, Gerritsen J, Kauffman HF. Induction of low density and upregulation of CD11b expression of neutrophils and eosinophils by dextran sedimentation and centrifugation. J Immunol Methods 1994; 167: 183-193.

29. Fearon DT, Collins LA. Increased expression of C3b receptors on polymorphonuclear leukocytes induced by chemotactic factors and by purification procedures. $J$ Immunol 1983; 130: 370-375.

30. Repo H, Jansson S-E, Leirisalo-Repo M. Flow cytometric determination of CD11b upregulation in vivo. $J$ Immunol Methods 1993; 164: 193-202.

31. Berends C, Hoekstra MO, Dijkhuizen B, de Monchy JGR, Gerritsen J, Kauffman HF. Expression of CD35 (CR1) and CD11b (CR3) on circulating neutrophils and eosinophils from allergic asthmatic children. Clin Exp Allergy 1993; 23: 926-933.

32. Barnes PJ. New concepts in the pathogenesis of bronchial hyperresponsiveness and asthma. J Allergy Clin Immunol 1989; 83: 1013-1026.

33. de Grooth BG, Terstappen LWM, Puppels GJ, Greve J. Light scattering polarization, a new parameter in flow cytometry. Cytometry 1987; 8: 539-544.
34. Altieri DC, Edgington TS. A monoclonal antibody reacting with distinct adhesion molecules defines a transition in the functional state of the receptor CD11b/CD18 (Mac-1). J Immunol 1988; 141: 2656-2660.

35. Spertini O, Kansas GF, Munro JM, Griffin JD, Tedder TF. Regulation of leukocyte migration by activation of the leukocyte adhesion molecule-1 (LAM-1), selectin. Nature 1991; 349: 691-694.

36. Dent G, Giembycz MA, Evans PM, Rabe KF, Barnes PJ. Suppression of human eosinophil respiratory burst and cyclic AMP hydrolysis by inhibitors of type IV phosphodiesterase: interaction with the beta-adrenoceptor agonist, albuterol. J Pharmacol Exp Ther 1994; 271: $1167-1174$

37. Sullivan P, Bekir S, Jaffar Z, Page C, Jeffery P, Costello J. Anti-inflammatory effects of low-dose oral theophylline in atopic asthma. Lancet 1994; 343: 10061008.

38. Wollner A, Wollner S, Smith JB. Acting via A2 receptors, adenosine inhibits the upregulation of MAC-1 (CD11b/CD18) expression on fMLP-stimulated neutrophils. Am J Respir Cell Mol Biol 1993; 9: 179-185.

39. Brown GE, Reed EB, Lanser ME. Neutrophil CR3 expression and specific granule exocytosis are controlled by different signal transduction pathways. J Immunol 1991; 147: 965-971.

40. Kuehl FA Jr, Zanetti ME, Soderman D, Miller DK, Ham EA. Cyclic AMP-dependent regulation of lipid mediators in white cells: a unifying concept for explaining the efficacy of theophylline in asthma. Am Rev Respir Dis 1987; 136: 210-213.

41. Takayama H, Trenn G, Sitkovsky MV. Locus of inhibitory action of cAMP-dependent protein kinase in the antigen receptor triggered cytotoxic T-lymphocyte pathway. J Biol Chem 1988; 263: 2330-2336.

42. Della Bianca V, De Togni P, Grzeskowiak M, Vicentini LM, Di Virgilio F. Cyclic AMP inhibition of phosphoinositide turnover in human neutrophils. Biochim Biophys Acta 1986; 886: 441-447.

43. Verghese MW, Charles L, Jakoi L, Dillon SB, Snyderman $\mathrm{R}$. Role of a guanine nucleotide regulatory protein in the activation of phospholipase $\mathrm{C}$ by different chemoattractants. J Immunol 1987; 138: 4374-4380.

44. Koenderman L, Yazdanbakhsh M, Roos D, Verhoeven AJ. Dual mechanisms in priming of the chemoattractant-induced respiratory burst in human granulocytes: a $\mathrm{Ca}^{2+}$-dependent and a $\mathrm{Ca}^{2+}$-independent route. J Immunol 1989; 142: 623-628.

45. Berger M, Birx DL, Wetzler EM, O'Shea J, Brown EJ, Cross AS. Calcium requirements for increased complement receptor expression during neutrophil activation. J Immunol 1985; 135: 1342-1348.

46. Shalit M, Von Allmen C, Atkins PC, Zweiman B. Plateletactivating factor increases expression of complement receptors on human neutrophils. J Leukoc Biol 1988; 44: 212-217.

47. Yukawa T, Kroegel C, Chanez P, et al. Effect of theophylline and adenosine on eosinophil function. Am Rev Respir Dis 1989; 140: 327-333.

48. Cronstein BN, Kramer SB, Weissmann G, Hirschhorn R. Adenosine: a physiological modulator of superoxide anion generation of human neutrophils. J Exp Med 1983; 158: $1160-1177$.

49. Liu MC, Hubbard WC, Proud D, et al. Immediate and late inflammatory responses to ragweed antigen challenge of the peripheral airways in allergic asthmatics: cellular, mediator, and permeability changes. Am Rev Respir Dis 1991; 144: 51-58. 